\title{
Drug-induced Hemolysis in G6PD Deficiency: an Unusual Presentation of a Common Clinical Condition
}

\author{
Anudeep Padakanti ${ }^{1}$, Ashok Shenoy K ${ }^{2, *}$, Ashwin Kamath², Mahabala Chakrapani ${ }^{1}$
}

\begin{abstract}
Glucose-6-phosphate dehydrogenase (G6PD) deficiency can present a diagnostic dilemma owing to the varying degrees of disease severity and the wide range of precipitating factors. Here, we report a case of a 56-year-old man who presented with signs and symptoms of heart failure and, during the course of treatment, developed intravascular hemolysis. On investigation, he was found to be G6PD deficient. Following discontinuation of the fixed-dose combination of isosorbide dinitrate and hydralazine, the clinical condition of the patient improved, and there were no further episodes of hemolysis. The case highlights the need for a high degree of suspicion of G6PD deficiency in patients with unexplained signs and symptoms of intravascular hemolysis.
\end{abstract}

\section{KEYWORDS}

G6PD deficiency; isosorbide dinitrate; hydralazine; intravascular hemolysis

\section{AUTHOR AFFILIATIONS}

${ }^{1}$ Department of Medicine, Kasturba Medical College, Mangalore, Manipal Academy of Higher Education, Manipal, Karnataka, India

2 Department of Pharmacology, Kasturba Medical College, Mangalore, Manipal Academy of Higher Education, Manipal, Karnataka, India

* Corresponding author: Department of Pharmacology, Kasturba Medical College, Mangalore, Manipal Academy of Higher Education, Manipal, Karnataka, India - 575001; e-mail: ashok.shenoy@manipal.edu 


\section{INTRODUCTION}

Glucose-6-phosphate dehydrogenase (G6PD) deficiency is the most common inherited and sex-linked enzymopathies (1). The identification of G6PD deficiency was the result of several converging events, one being the observation that some, but not all, individuals developed hemolysis on administration of 8 -aminoquinoline antimalarials (2). The characteristic history and the availability of rapid diagnostic kits for detection of the enzyme deficiency have made the disease detection and management easy in the clinical setting, especially in malaria endemic areas, where the patients typically present with acute symptoms of intravascular hemolysis following culprit drug administration. Owing to the varying degrees of disease severity and the wide range of precipitating factors, the disease sometimes poses a diagnostic dilemma (3-5). Here, we report an unusual presentation of a case of drug-induced hemolysis due to G6PD deficiency in a 56-year-old patient presenting with symptoms of heart failure.

\section{CASE REPORT}

A 56-year-old male patient of Asian race presented to the General Medicine outpatient department of Kasturba Medical College Hospital, Mangalore, India, with complaints of swelling of both feet and breathlessness on exertion since four days. He was a known case of type 2 diabetes mellitus on oral medications, glimepiride and metformin. There was no significant past history or family history of any medical illness; no history of hospitalization or prolonged medication intake. On examination, his pulse rate was 120 beats per min and blood pressure was 128/80 mmHg. Jugular venous pulse was elevated, and there was bilateral pitting edema up to the ankle. On systemic examination, there were bilateral basal crepitations, hepatomegaly, and third heart sound was heard in the mitral area. Considering the presenting complaints and the physical examination findings, cardiologist opinion was sought, and two-dimensional echocardiography was done. The echocardiography was suggestive of con- gestive cardiac failure with ischemic heart disease and severe left ventricular dysfunction with an ejection fraction of $30 \%$. A thin rim of pleural and pericardial effusion was also seen. Ultrasound abdomen showed a normal-sized spleen with minimal ascites and mild pleural effusion. Liver was $14 \mathrm{~cm}$ in size with normal echotexture. He was started on tablet digoxin $0.25 \mathrm{mg}$ half-tablet on alternate days, a fixed-dose combination of isosorbide dinitrate $20 \mathrm{mg}$ plus hydralazine $37.5 \mathrm{mg}$ thrice daily, injection furosemide $20 \mathrm{mg}$ intravenously thrice daily, low dose aspirin $75 \mathrm{mg}$ once daily, atorvastatin $10 \mathrm{mg}$ once daily, and ramipril $5 \mathrm{mg}$ once daily. On day 1 , the haemoglobin level was $118 \mathrm{~g} / \mathrm{L}$; the rest of the blood parameters were normal. On day 2 of the in-hospital stay, he complained of 4-5 episodes of vomiting, which was treated symptomatically. On day 3 , the vomiting persisted, and on day 4, physical examination revealed icterus; however, the urine appeared clear. The patient was scheduled to undergo coronary angiography, but the procedure was withheld, and blood investigations ordered, which showed a haemoglobin level of $94 \mathrm{~g} / \mathrm{L}$ with a total bilirubin of $64.12 \mathrm{micromol} / \mathrm{L}$. The patient was evaluated to ascertain the cause for the drop in hemoglobin level. Stool occult blood was found to be negative. Peripheral smear showed normocytic normochromic anemia with features suggestive of hemolytic anemia. Also, elevated total bilirubin was seen, predominantly unconjugated. The possibility of drug-induced intravascular hemolysis was considered, and a workup for G6PD deficiency was done. Using the dye decolorization test, the patient was found to be positive for G6PD deficiency. Among the prescribed medications, the fixed-dose combination of isosorbide dinitrate plus hydralazine was suspected to be the culprit drug based on the limited evidence available. The drug was withheld, and the rest of the medications were continued. On days 7 and 8, there was a further drop in hemoglobin level to $62 \mathrm{~g} / \mathrm{L}$. The opinion of a hematologist was sought, and two units of packed cell transfusion were given. Then, the patient was started on antioxidants and vitamin supplements. No further drop in the hemoglobin level was observed on days 7 and 8 , and he was discharged from the hospital with the following medications: ramipril, trimetazidine, furosem-

Tab. 1 Laboratory investigations performed during the hospital stay.

\begin{tabular}{|l|l|l|l|l|l|}
\hline $\begin{array}{l}\text { Day of in-hospital } \\
\text { stay }\end{array}$ & $\begin{array}{l}\text { Total bilirubin } \\
\text { (micromol/L) }\end{array}$ & $\begin{array}{l}\text { Direct bilirubin } \\
\text { (micromol/L) }\end{array}$ & $\begin{array}{l}\text { Indirect bilirubin } \\
\text { (micromol/L) }\end{array}$ & $\begin{array}{l}\text { Haemoglobin } \\
\text { (g/L) }\end{array}$ & Other laboratory investigations \\
\hline Day 1 & - & - & & 118 & - \\
\hline Day 4 & 64.12 & 17.78 & 46.34 & 94 & $\begin{array}{l}\text { Coombs test - negative } \\
\text { Mean corpuscular volume 75.1 fL (reference } \\
\text { range, 83.0 -101.0) } \\
\text { LDH level 354 U/L (reference range, 0-250) }\end{array}$ \\
\hline Day 5 & 86.18 & 23.42 & 3.67 & $\begin{array}{l}\text { Peripheral smear - microcytic hypochromic } \\
\text { with neutrophilic leucocytosis and features } \\
\text { of hemolysis. No Heinz bodies seen. } \\
\text { G6PD - decolorization > 6 hours }\end{array}$ \\
\hline Day 6 & & & 84 & - \\
\hline Day 7 & 87.21 & 30.95 & 3.29 & 75 & Stool occult blood - negative \\
\hline Day 8 & 108.58 & 56.60 & 3.04 & 74 & Blood transfusion given \\
\hline Day 9 & 51.64 & 26.16 & 1.49 & 62 & - \\
\hline
\end{tabular}


ide, glimepiride + metformin, ivabradine, pantoprazole, ferrous sulphate, folic acid, and vitamin C tablets. During the follow-up visit two weeks later, his hemoglobin level was $112 \mathrm{~g} / \mathrm{L}$, and he was hemodynamically stable. The haemoglobin increased to $130 \mathrm{~g} / \mathrm{L}$ after a month, suggesting that the initial anemia was due to iron deficiency. Table 1 shows the important lab investigation values during the course of the hospital stay.

\section{DISCUSSION}

G6PD is not an uncommon condition in India. The frequency of occurrence in India is 8.5\% (6). This is in agreement with the global estimated prevalence of $8 \%$ in malaria endemic countries (7). G6PD deficiency can be classified into five classes with class I representing severe deficiency, characterized by chronic nonspherocytic hemolytic anemia and normal erythrocyte function (8). Class IV corresponds to normal enzyme activity and, class V, increased activity. Class II G6PD deficiency, with less than 10\% of normal enzyme activity, is more common in Asians and the Mediterranean population. The case reported here is unique in that this middle-aged patient had no previous history suggestive of hemolysis and, during the treatment of the presenting complaints, developed intravascular hemolysis to drug(s) not commonly implicated in causing hemolysis. Except for a report of hemolysis in two patients, there is no substantial evidence to avoid the use of isosorbide dinitrate (9). While some suggest avoiding the drug due to the possible risk of hemolysis, not all have included it in the list of drugs to be avoided $(10,11)$. There is, however, a recent report of late-life presentation of hemolysis due to G6PD deficiency following administration of intravenous nitroglycerin (12). There is limited evidence implicating hydralazine in G6PD hemolysis (1315). In fact, we were unable to find any reports of hydralazine-induced hemolysis in G6PD deficiency. The drug has been implicated in hemolysis due to the formation of immune complexes. However, this mechanism is unlikely to be responsible for the acute intravascular hemolysis seen in this patient (13). Also, the Coombs test was negative. The drug monograph of hydralazine states the following hematological adverse reactions: Blood dyscrasias, consisting of a reduction in hemoglobin and red cell count, leukopenia, agranulocytosis, and purpura (16). There is no recommendation regarding its use in patients with $\mathrm{G} 6 \mathrm{PD}$ deficiency. The initial episode of vomiting was suspected to be due to the irritant effect of the drugs prescribed. However, the persistence of vomiting followed by the occurrence of jaundice raised the suspicion of intravascular hemolysis. We decided to evaluate the G6PD status of the patient as no other cause for intravascular hemolysis was apparent. Dechallenge confirmed the diagnosis as there was no further intravascular hemolysis, barring the immediate period following drug withdrawal, as determined via the hemoglobin levels, and there was an improvement in the hemoglobin status subsequently despite the continuation of all the other drugs. While furosemide is also known to cause hemolysis in G6PD deficient patients, the improvement in the patient's condition despite the con- tinuation of furosemide rules it out as the precipitating drug (17). A rechallenge was not performed as there was no pharmacological compulsion for continuing with isosorbide dinitrate plus hydralazine and, hence, would be unethical. Based on the WHO-UMC causality assessment scale and the Naranjo scale, the causality was judged to be probable. We were unable to determine the class of G6PD enzyme variant and confirm which of the two drugs in the fixed-dose combination caused the adverse event.

This case highlights the importance of suspecting the presence of G6PD deficiency in an unrelated clinical setting precipitated by a drug not well known to cause oxidative hemolysis. In population with a G6PD deficiency of $3-5 \%$ or more in males, screening of new born infants is recommended (8). Fluorescent spot test, a qualitative assay, is a suitable test for the detection of G6PD deficiency, as compared to the more definitive quantitative tests, in heterozygous males and homozygous females in high-burden, resource-poor areas (18). Early recognition using simple laboratory tests will avoid unnecessary investigations and prolonged hospital stay.

\section{CONFLICTS OF INTEREST}

The authors have no conflicts of interest to declare.

\section{REFERENCES}

1. Hwang S, Mruk K, Rahighi S, et al. Correcting glucose-6-phosphate dehydrogenase deficiency with a small-molecule activator. Nat Commun 2018; 9(1): 4045 .

2. Beutler E. Glucose-6-phosphate dehydrogenase deficiency: a historical perspective. Blood 2008; 111(1): 16-24.

3. Merdin A, Avci F, Guzelay N. Glucose-6-phosphate dehydrogenase deficiency presented with convulsion: a rare case. Hematol Rep 2014; 6(1): 5266.

4. Eziokwu AS, Angelini D. New Diagnosis of G6PD Deficiency Presenting as Severe Rhabdomyolysis. Cureus 2018; 10(3): e2387.

5. Ainoon O, Boo NY, Yu YH, Cheong SK, Hamidah HN. G6PD deficiency with hemolytic anemia due to a rare gene deletion - a report of the first case in Malaysia. Hematology 2006; 11(2): 113-8.

6. Kumar P, Yadav U, Rai V. Prevalence of glucose-6-phosphate dehydrogenase deficiency in India: an updated meta-analysis. EJMHG 2016; 17(3): 295-302.

7. Howes RE, Piel FB, Patil AP, et al. G6PD deficiency prevalence and estimates of affected populations in malaria endemic countries: a geostatistical model-based map. PLoS Med 2012; 9(11): e1001339.

8. Glucose-6-phosphate dehydrogenase deficiency. WHO Working Group. Bull World Health Organ 1989; 67(6): 601-11.

9. Aderka D, Garfinkel D, Bograd H, Friedman J, Pinkhas J. Isosorbide dinitrate-induced hemolysis in G6PD-deficient subjects. Acta Haematol 1983; 69(1): 63-4.

10. Youngster I, Arcavi L, Schechmaster R, et al. Medications and glucose-6-phosphate dehydrogenase deficiency. Drug Saf 2010; 33(9): 713-26.

11. Glader B. Diagnosis and management of glucose-6-phosphate dehydrogenase (G6PD) deficiency [Internet]. UpToDate. 2019 [cited 10 March 2019]. Available from: https://www.uptodate.com/contents /diagnosis-and-management-of-glucose-6-phosphate-dehydroge nase-g6pd-deficiency

12. Benchimol M, Madeira LB, de Oliveira-Souza R. Late-Life Presentation of Unsuspected G6PD Deficiency. Case Rep Crit Care 2018; 2018 : 8198565.

13. Drugs to avoid in G6PD deficiency [Internet]. Taiwan: MIMS; 2019 [cited 10 March 2019]. Available from: http://www.cych.org.tw /pharm/MIMS\%20Summary\%20Table-G6PD.pdf

14. Dhaliwai G, Cornett PA, Tierney LM. Hemolytic anemia. Am Fam Physician 2004; 69: 2599-608.

15. G6PD Deficiency [Internet]. UAE; [cited 10 March 2019]. Available from: http://www.cags.org.ae/gme1bdeng6pd.pdf 
16. Hydralazine [Internet]. UpToDate. 2019 [cited 10 March 2019] Available from: https://www.uptodate.com/contents/hydrala zine-drug-information?search=hydralazine\&source=panel_search result\&selectedTitle $=1 \sim 119 \&$ usage_type $=$ panel\&kp_tab=drug general\&display_rank=1\#F179429
17. Balderia PG, Wongrakpanich S, Patel M, Stanek M. Healing the orphaned heart: heart failure in a patient with glucose-6-phosphate dehydrogenase deficiency. BMJ Case Rep 2015; 2015: bcr2015209365.

18. LaRue N, Kahn M, Murray M, et al. Comparison of quantitative and qualitative tests for glucose-6-phosphate dehydrogenase deficiency. Am J Trop Med Hyg 2014; 91(4): 854-61. 